\title{
Real-time hydrocarbons sweet spot identification in shale formations while drilling horizontally using geo-mechanical and geophysical parameters
}

\section{Alberto Lopez Manriquez*}

The Wayne H. King Department of Chemical and

Natural Gas Engineering,

Texas A\&M University-Kingsville, 700 University Blvd., Kingsville, TX 78363-8202, USA

Email: Alberto.lopezmanriquez@tamuk.edu

*Corresponding author

\section{Kamy Sepehrnoori}

Petroleum and Geosystems Engineering Department, The University of Texas at Austin, 200 E. Dean Keeton St., Stop C0300, Austin, TX 78712-1585, USA

Email: kamys@mail.utexas.edu

\begin{abstract}
This work presents an innovative comprehensive approach to properly identify intervals with the most favourable potential and properties to produce hydrocarbons known as hydrocarbons 'sweet spots'. The approach is applied to horizontal wells in shale formations but not limited to this scenario. One of the singularities of this work rests on the proposal that rock properties are obtained from logging while drilling (LWD) techniques. This self-supported methodology is applied to characterise the reservoir from the stand points of geo-mechanics, geophysics, and geopressure. Rock and fluid properties measured along the horizontal section of the well while drilling served to generate a synthetic acoustic log. Changes in trends of geo-mechanical and geophysical properties such as brittleness and acoustic impedance are used as indicators of hydrocarbons presence. Ultimately, the methodology is proposed to properly select the intervals to complete and to optimise the length of the horizontal section of the well. [Received: March 23, 2017; Accepted: September 5, 2018]
\end{abstract}

Keywords: hydrocarbons sweet spot; geo-mechanics; brittleness; acoustic impedance; logging while drilling; LWD; unconventional shales; reservoir pressure prediction.

Reference to this paper should be made as follows: Lopez Manriquez, A. and Sepehrnoori, K. (2020) 'Real-time hydrocarbons sweet spot identification in shale formations while drilling horizontally using geo-mechanical and geophysical parameters', Int. J. Oil, Gas and Coal Technology, Vol. 24, No. 3, pp.377-393.

Biographical notes: Alberto Lopez Manriquez is an Associate Professor in the Chemical and Natural Gas Engineering Department, Texas A\&M University-Kingsville. He holds a $\mathrm{PhD}$ in Petroleum Engineering from the 
University of Texas at Austin. His publications are oriented to hydraulic fracturing, pore pressure prediction for reservoir description and management and well planning and monitoring during drilling and completion operations. $\mathrm{He}$ has contributed independently and jointly in the subjects of geomechanics and geopressure. His recent publications contain documented applications to real scenarios, especially in unconventional resources such as shale.

Kamy Sepehrnoori is a Professor and Associate Department Chair, at W.A. (Monty) Moncrief Centennial Endowed Chair in Petroleum Engineering. He holds a PhD in Petroleum Engineering from the University of Texas at Austin. His current research is focused on development and application of compositional reservoir simulators for enhanced oil recovery, modelling of asphaltene deposition in reservoirs and wellbores, development and application of reservoir simulators for naturally fracture reservoirs, EOR processes for heavy oil, development and application of reservoir simulators for unconventional resources, development of parallel reservoir simulators and $\mathrm{CO}_{2}$ sequestration.

\section{Introduction}

In the last decade, the oil and gas industry began considering shales as new production horizons, not only as source rocks. Since then, many authors have covered the study of shales from different standpoints and numerous technical papers have been published. Glaser et al. (2014) provide an extensive review about the costs and risks associated with placing horizontal wells optimally in shale reservoirs. They assert that two factors control the economic viability of a shale play. These two factors are reservoir quality (RQ) and completion quality (CQ). According to them, RQ is defined for organic shale reservoirs as the ability to produce hydrocarbons economically after hydraulic fracture stimulation. CQ helps to predict successful reservoir stimulation through hydraulic fracturing. These two factors depend on mineralogy, petrophysical, geo-mechanical, and geophysical properties of formations. Glaser et al. (2014) emphasise the need for characterising properly shale plays to identify intervals with high RQ and CQ. In addition to these two factors, reservoir pressure plays an important role in the production of hydrocarbons. A reservoir without enough energy will require additional downhole equipment and treatments to produce effectively, which will affect the economic viability of a project.

This study focuses on establishing a self-supported methodology based on geo-mechanical and geophysical rock properties to efficiently identify hydrocarbon sweet spots while drilling horizontally. Adequate reservoir pressure estimation is proposed to complement the analysis. Lopez and Sepehrnoori (2015) developed a novel method based on the diffusivity equation in conjunction with information from well logs to estimate reservoir pressure in conventional and complex unconventional geological scenarios. Reliable identification of sweet spots is important to improve selection of the intervals to be completed and to optimise the length of a horizontal well.

Traditionally, determination of the length of a horizontal well has been addressed under the postulate that more production should be obtained due to more area of reservoir connected to the wellbore and to variations in the drainage patterns of flow within the reservoir. Long horizontal wellbores are drilled expecting that this condition would be accomplished. Many authors have contributed to this topic and have provided analytical 
and numerical solutions to estimate productivity from horizontal wells. Lu et al. (2013) and Economides et al. $(1998,2013)$ provide a comprehensive review of the literature discussing some of the different inflow performance relationships (IPR) useful for estimating productivity from horizontal wells. Economides et al. discussed analytical steady-state and pseudo-steady state flow models providing detailed analysis about the influence on productivity of parameters, such as vertical permeability, permeability anisotropy in the horizontal plane, thickness of producing formation, magnitude and orientation of in-situ stresses, and well length. Economides et al. (2013) reviewed several models applicable to forecasting horizontal inflow performance. They reviewed Joshi's and Furui's models for steady-state flow condition and Babu's and Odeh's models for pseudo steady-state flow condition. Economides et al. model covers scenarios for various single, multilateral, and multi-branch horizontal well configurations by including a 'shape factor'. This model allows the inclusion of vertical to horizontal permeability anisotropy and permeability anisotropy in the horizontal plane. It also takes into consideration damage to the producing formation created during the drilling and completion steps of the well. Formation damage is included as skin factor. The complete and detailed treatment of this modelling technique can be found in their original publications (Economides et al., 1998, 2013).

The models discussed previously provide a primary and reliable tool to investigate the effect of different well configurations and reservoir parameters on the productivity of a horizontal well. However, all such models assume that reservoir properties and reservoir pressure are homogeneously distributed along the producing horizon. This assumption is not satisfied in most real scenarios. Instead, variations in reservoir pore pressure should be expected in heterogeneous formations.

\section{Geo-mechanical reservoir characterisation}

\subsection{Modelling brittleness of rock}

When a cross dipole-sonic (DSI) tool is deployed into a wellbore, at least both the compression and the shear head acoustic waves can be recorded. Parra and Domasck (2009) and many other researchers stated that these two head acoustic waves have been identified as key parameters to quantify elastic properties of rock. DSI tool was deployed in the vertical pilot well and velocities of the compressional wave, $V_{p}$ and of the shear wave, $V_{s}$, were recorded. Authors recognise that direct measurement of geo-mechanical properties from a core sample in the laboratory provides valuable information to calibrate results obtained from well logging techniques. However, information from core samples was not available. In this respect, several authors, including Fjaer et al. (2008), Sone and Zoback (2013), and Zhang and Bentley (2005) have discussed the issues involved when dynamic values of Young's modulus, $E$ and Poisson's ratio, $v$ are used for prediction purposes, instead of static values from laboratory tests. Zhang and Bentley suggested use of relationships to calculate the ratio of static over dynamic Poisson ratio for analysing difference between them. Sone and Zoback, while testing organic rich shales, concluded that the static Young's modulus and dynamic moduli elastic parameters generally decrease with clay and kerogen content. They also concluded that the unloading/reloading static modulus, in these rocks, correlate very well to the dynamic 
modulus in the samples tested. We computed Young's modulus, $E$, and Poisson's ratio, $v$ using equations (1) through (3) from $V_{p}$ and $V_{s}$ values (Colin and Darren 1997).

$$
\begin{aligned}
& v=\frac{V_{p}^{2}-2 V_{s}^{2}}{2\left(V_{p}^{2}-2 V_{s}^{2}\right)} \\
& E=2 \mu_{L}(1+v)
\end{aligned}
$$

where

$$
\mu_{L}=\rho V_{s}^{2}
$$

It is important to point out that the work related to this subject has been addressed by other researchers as an attempt to better characterise Young's modulus and Poisson's ratio. Baldino et al. (2017) and Shahri and Miska (2015) developed analytical solutions to the diffusivity equation to obtain in-situ Poisson's ratio from interference well tests. They concluded that Poisson's ratio is strongly dependent on stress and deformation boundary conditions. Shahri and Miska reported that Poisson's ratio is the most important rock property for geo-mechanical modelling of reservoirs. They proposed that computing an average Poisson's ratio using well testing techniques should help overcome the limitations imposed when these rock properties are computed using information from well logs, fracturing data, or core samples, which is limited to the near-wellbore region. These techniques are highly recommended for future work to improve the rock properties characterisation.

Issues and concerns related to interpretation and handling of sonic information coming from deviated wells are not present in this case study because the source sonic data employed to generate the synthetic log come from the vertical pilot well. Many experts in acquisition and processing of acoustic information from rocks have addressed this subject. Miller et al. (2011) and Parra and Domasck (2009) reported conflicts regarding interpretation of sonic logs in deviated wells in anisotropic media. Miller et al. explain that this confusion comes from the principle that wave fronts radiated from a point source are not generally spherical. Parra and Domasck proposed a transformed boundary integral equation (TBIE) method to simulate cross-dipole responses representing wells drilled vertically into formations with horizontal layering, and for horizontal wells drilled into formations that have vertical fractures.

Brittleness of rock is a parameter used to characterise unconventional shale plays. Herwanger et al. (2015) and Perez-Altamar (2013) among others authors have discussed the applicability and uses of this brittleness index and other parameters defining brittleness of rock. Glaser et al. (2014) stated that CQ is highly influenced by elastic rock properties, such as Young's modulus, Poisson's ratio, among other relevant factors (in the likes of natural fractures and in-situ stresses). Therefore, brittleness is closely related to $\mathrm{CQ}$, since it helps to predict successful reservoir stimulation through hydraulic fracturing. Herwanger et al. (2015) mentioned that in the recent literature, definitions for brittleness index have been grouped in three predominant categories. The three groups characterise the brittleness of rocks from their elastic properties, their petrophysical 
properties, and their strength properties, respectively. Herwanger et al. elaborate the correct use of this index with respect to applications in hydraulic fracturing. They conclude that in addition to brittleness index, the 'in-situ' state of stresses, the strength of rock, pre-existing planes of weakness, such as natural fractures and weak bed boundaries, and pore pressure, must be taken into account.

Herwanger et al. (2015) and Perez-Altamar (2013) presented a comprehensive review of methods of estimating brittleness from information obtained from seismic, from well logging, or from both. Particularly, Perez-Altamar (2013) states that it is necessary to estimate reliable and robust reservoir brittleness to combine information from well logs with geo-mechanical properties, such as Young's modulus and Poisson's ratio. Perez-Altamar accredits these statements to Grieser and Bray (2007) and Rickman et al. (2008). Perez-Altamar (2013) concluded in his publication that simultaneous inversion of surface seismic data not only differentiates shale from limestone but also is a very effective tool to discriminate between brittle and ductile shale intervals. He identified empirical approaches currently used to identify the transition from brittle to ductile behaviour, based on mineralogy using logs. He also concluded that micro seismic and production $\operatorname{logs}$ are important to analyse brittleness. Micro seismic reveals that hydraulically induced fractures preferentially populate brittle regions, while production logs show that brittle fractured zones produce more hydrocarbons.

Montaut et al. (2013) also presented a detailed review of the subject. Fracturability instead of brittleness of rock is introduced as the parameter to analyse CQ. They state that in shale gas formations, fracturability correlates with mineralogy and elastic properties of rocks. They also described that dynamic elastic properties, such as Young's modulus and Poisson's ratio, correlate in shale gas and concluded that Young's modulus estimated from sonic logs is reliable for estimation of fracturability of isotropic rocks.

Grieser and Bray (2007) proposed brittleness average (BA). They also proposed normalised Young's modulus and Poisson's ratio, described by equations (4) and (5).

$$
\begin{aligned}
& E_{\text {brittleness }}=\frac{E-E_{\min }}{E_{\max }-E_{\min }} \\
& v_{\text {brittleness }}=\frac{v-v_{\max }}{v_{\min }-v_{\max }}
\end{aligned}
$$

where $E_{\max }, E_{\min }, v_{\max }$ and $v_{\min }$ are the maximum and minimum Young's modulus and Poisson's ratio recorded in the logged formation.

BA can be computed according to the following expression;

$$
B A=\frac{\left(E_{\text {brittleness }}+v_{\text {brittleness }}\right)}{2}
$$

According to the summary presented previously, we conclude that BA is a valid parameter to characterise rock formation for the shale play environment, the subject of this study. The 'in-situ' state of stresses, the geo-mechanical and geophysical properties of rock and the reservoir pressure are all taken into consideration in the modelling. 


\section{Geophysical reservoir characterisation}

\subsection{Modelling acoustic impedance}

Seismic surveys are intended to correctly image the subsoil structure and to correctly characterise the amplitudes of the reflected acoustic waves. From these amplitudes seismic attributes can be derived. One common attribute computed is amplitude variation with offset (AVO). Chopra and Pruden (2003) presented the results of AVO inversion to estimate Lame parameters using a probabilistic neural network solution. AVO inversion is a technique used by geophysicists on seismic data to determine rock properties and to identify hydrocarbons. Chopra and Pruden (2003) concluded that their results contributed positively to the estimation of relative sand distribution, porosity, and fluid content estimates. As well as Chopra and Pruden, Sayers et al. (2015) and Guo et al. (2013) implemented AVO inversion to identify lithology and pore-fluid type from seismic and well logs based on Lame parameters. Chopra and Pruden state that impedance reflectivities are related to Lame parameters of incompressibility $\left(\lambda_{L}\right)$ and rigidity $\left(\mu_{L}\right)$ by the relationships $\lambda_{L} \rho=I_{p}^{2}-2 I_{s}^{2}$ and $\mu_{L} \rho=I_{s}^{2}$, where $\rho$ is bulk density, $I_{p}$ is acoustic impedance, and is shear impedance.

Related to the subject of hydrocarbons identification, Ogiesoba (2014, 2015) demonstrated that hydrocarbon sweet spots are characterised by high resistivity, high total organic content/carbon (TOC), and high acoustic impedance. Ogiesoba (2015) discussed the relationship between rock physical properties and the instantaneous quality factor attribute, $Q$. The instantaneous quality factor is reported by Elapavuluri and Bancroft (2004) as the loss of energy per unit cycle and represented in standard form as follows:

$$
Q=\frac{\omega E_{S}}{-d E_{S} / d t}
$$

where $E_{S}$ is stored energy in the system, $d E_{S} / d t$ is rate of energy loss and $\omega$ is oscillatory frequency.

Ogiesoba (2015) emphasises that experts in scientific exploration groups recognise that $\mathrm{Q}$ is a very powerful tool for detection of hydrocarbons and identification of brittle zones within unconventional resource plays. In his paper, he presented results of the application of instantaneous $Q$ on the characterisation of the Austin Chalk and Eagle Ford Shale within the Maverick Basin in South Texas. He computed $Q$ from 3-D seismic data and calibrated his results using well logs. Results showed that $Q$ increases as acoustic impedance increases, suggesting that $Q$ can be used to identify brittle carbonate zones within shale intervals. In addition, he found linear relationship between $Q$ and TOC. When $Q$ increases, TOC increases. He concluded that $Q$ is a powerful tool that can be used in hydrocarbon exploration in any geologic setting. Based on Ogiesoba's findings, we suggest that accurate estimation of acoustic impedance should be used to identify hydrocarbon sweet spots. 


\section{Reservoir pressure modelling}

Measuring reservoir pressure directly along the horizontal is not a common practice. We consider that estimation of reservoir pressure all along the horizontal section of the well is important to define the quality of a reservoir (RQ). Implementation of traditional indirect methods to estimate reservoir pore pressure, while or after drilling the horizontal section, is not encouraged because they are not applicable due to shortcomings resulting from the empirical formulations they come from. For this reason, reservoir pressure was computed using equation (8). The details of the solution and applicability of this equation can be found in Lopez and Sepehrnoori (2015). Diffusivity comes from three different sources: hydraulic, mass, and thermal. A solution of the diffusivity equation was obtained by introducing Darcy's law to a mass balance on a system; the solution is given in equation (8). Since the system was assumed to be at equilibrium, both mass diffusion through the porous medium and temperature were neglected, allowing simplification to the diffusivity equation.

This section summarises the steps involved in computing reservoir pressure using data from well logs. Because acoustic properties from sonic logs are hardly available in horizontal boreholes, we processed information from gamma ray and resistivity obtained from LWD to generate a synthetic acoustic log. Multiple linear and higher than linear regression analyses based on these data were implemented in order to obtain synthetic velocities of the compressional wave, $V_{p}$, and of the shear wave, $V_{s}$. Reciprocal of the velocities are known as interval travel times (ITT), and also identified as $\Delta t$. The elastic constitutive model was applied to obtain geo-mechanical parameters of rock, such as Young's modulus and Poisson's ratio. Interval transit time $(\Delta t)$ values were introduced into the solution of the diffusivity equation to find a solution of pore pressure distribution as follows:

$$
P(z, t)=C_{n} e^{-\lambda t}\left(A \cos \left(\frac{z}{L} * \frac{\Delta t_{o}}{\Delta t_{\text {avg }}}\right)+B \sin \left(\frac{z}{L} * \frac{\Delta t_{o}}{\Delta t_{\text {avg }}}\right)\right)
$$

where

$$
\begin{aligned}
& \Delta t_{o} / \Delta t_{\text {avg }}=\sqrt{\lambda \mu / c^{2}} \\
& z \sqrt{\lambda \mu / c^{2}}=n \pi \text { and } \lambda=(n \pi c / z)^{2} / \mu . \\
& c^{2}=\frac{k}{\phi\left(C_{f}+C_{r}\right)} \text { where } C_{f} \text { and } C_{r} \text { are formation fluid and rock compressibilities, } \\
& \text { respectively. } \mu \text { is fluid dynamic viscosity, } \phi \text { is porosity and } k \text { is formation permeability. }
\end{aligned}
$$

\section{Results and discussion}

\subsection{Geo-mechanical and geophysical characterisation}

Acoustic well logs from the vertical pilot well were processed to obtain elastic properties of rock. Information coming from DSI tool in the vertical pilot well was processed to obtain $V_{p}$ and $V_{s}$. These two parameters were used to compute dynamic values of 
Poisson's ratio, $v$ and Young's modulus, E. Figures 1(a) and 1(b) show the profiles of these two computed parameters in the vertical pilot well. Dynamic $v$ and $E$ computed values were used in this work for calculations based on the concept and definition of brittleness expressed in equation (6). BA is defined according to the normalised values of Young's modulus and Poisson's ratio. Jansen (2014) reported values of Eagle Ford properties obtained in laboratory tests on seven samples. These reported values correspond to Eagle Ford but do not correspond to the Maverick basin area. Therefore, differences

between computed and Jansen's reported values are expected. The overall values reported by Jansen after analysing the samples were as follows: average Young's modulus $=2.28$ E 06 psi and average Poisson's ratio $=0.206$.

Figure 1 Dynamic values of Poisson's ratio, $v$ Young's modulus, $E$ obtained from direct (a) $V_{p}$ and (b) $V_{s}$ measurements in the vertical pilot wellbore (see online version for colours)

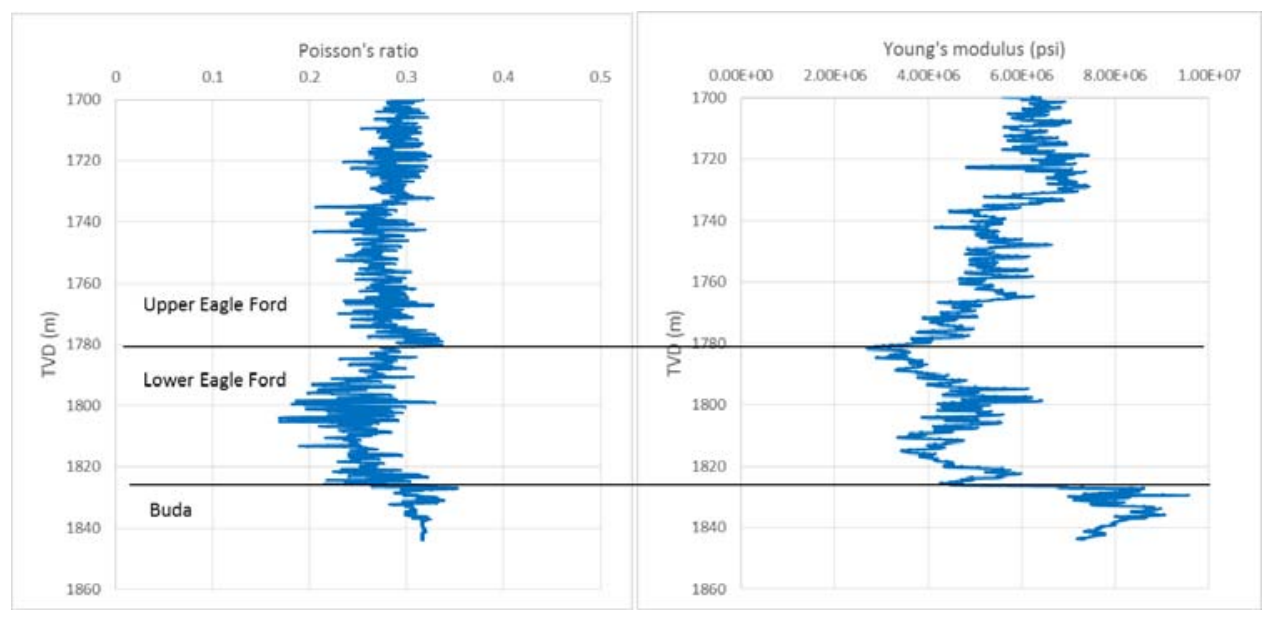

(a)

(b)

Once Young modulus and Poisson's ration were computed and calibrated for the vertical pilot well, the next step was to correlate them horizontally. Acoustic tools were not deployed in the horizontal section while drilling because the risks and high costs associated with this practice. Therefore, a synthetic acoustic log was generated to attempt a geo-mechanical characterisation of the formation all along the horizontal section of the well (inside Eagle Ford shale).

To create the synthetic acoustic log, data captured from electrical, acoustic, and radioactive logging tools from the vertical pilot open hole were analysed. Gamma ray, resistivity, and neutron values were recorded using LWD technique in the horizontal wellbore. Based on the available information, linear, quadratic, and cubic equations were investigated to match the compressional wave, $V_{p}$, and the shear wave, $V_{s}$ measured in the vertical pilot to select the appropriate model. After analysing and comparing results, the quadratic model was selected to generate the synthetic velocity model. Cubic equations did not provide much better fit of the results.

The equations for interval transit times that best fitted measured values are the following: 


$$
\begin{aligned}
\Delta t_{p} & =599.926+3.496(G R)-0.008\left(G R^{2}\right) 2.372\left(r_{o}\right)+0.005\left(r_{o}^{2}\right) \\
& -499.345(R H O B)+114.229\left(R H O B^{2}\right)-0.002+0.002\left(G R \times r_{o}\right) \\
& -1.069(G R \times R H O B)-1.177\left(r_{o} \times R H O B\right)
\end{aligned}
$$

and

$$
\begin{aligned}
\Delta t_{s}= & 1,797.750+2.761(G R)-0.006\left(G R^{2}\right)+2.575\left(r_{o}\right)+0.010\left(r_{o}^{2}\right) \\
& -1,424.590(R H O B)+305.565\left(R H O B^{2}\right)+0.001\left(G R \times r_{o}\right) \\
& -0.854(G R \times R H O B)-1.599\left(r_{o} \times R H O B\right)
\end{aligned}
$$

where $G R$ and $r_{o}$ are gamma ray and resistivity readings, respectively, while $R H O B$ is bulk density.

Figures 2(a) and 2(b) show respectively $\Delta t_{p}$ and $\Delta t_{s}$ synthetic values computed using equations (10) and (11) compared against those measured in the vertical pilot. It was found that computed synthetic values correlate very well with the actual measured $\Delta t_{p}$ and $\Delta t_{s}$ values. The small differences observed in Figures 2(a) and 2(b) between acquired data and synthetic values for transit times can be attributed to several reasons, such as horizontal borehole environment effects, quality of the information collected with LWD, lack of acoustic data in the horizontal section of the well, and regression techniques applied to data.

Figure 2 (a) $\Delta t_{p}$ and (b) $\Delta t_{s}$ synthetic values compared against those measured in the vertical pilot well (see online version for colours)

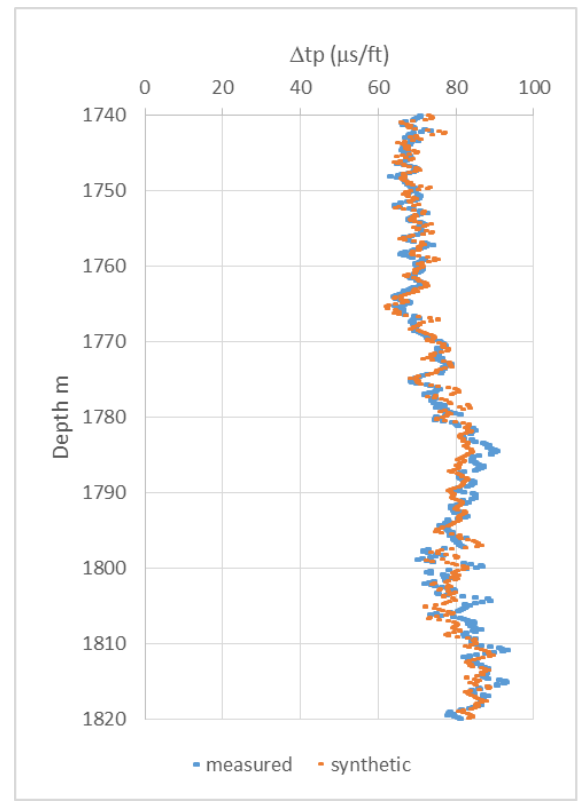

(a)

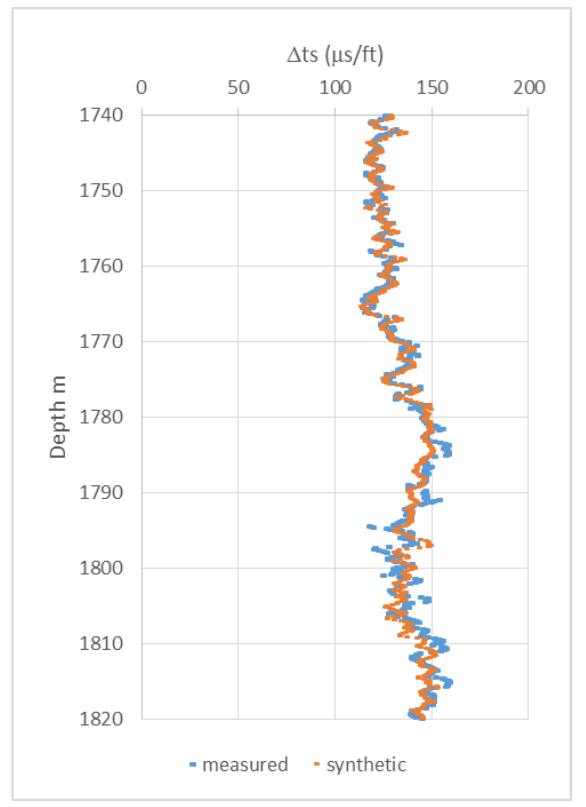

(b)

Regarding borehole environmental effects, we rely on the LWD information collected from the well. We were unable to analyse the quality of the logs since we had limited 
access to this information. These borehole environmental effects on the quality of well logging information are well documented. The lack of acoustic data in the horizontal wellbore might be a reason for small differences. As it can be seen on equations (10) and (11), only gamma ray, resistivity, and bulk density values were introduced into these equations. This is a limitation when LWD technique is applied to the horizontal section of a wellbore. Therefore, a perfect match between measured $\Delta t_{p}$ and $\Delta t_{s}$ values and computed synthetic values is not easy to obtain. Different types of regressions from linear, quadratic, to cubic equations were implemented.

Figures 3(a) and 3(b) show synthetic values of Poisson's ratio, $v$ and Young's modulus, $E$, computed with equations (4) through (6) against those $v$ and $E$ values obtained from direct measurements in the vertical pilot. For simplicity of analysis, only computed values along Eagle Ford horizon are shown. It can be seen from Figures 3(a) and 3(b) that synthetic and actual measured $v$ and $E$ values also correlate well. There is no doubt that if more information were available from LWD other than gamma ray, resistivity, and bulk density, more accurate equations for interval transit times could be obtained for an improved reservoir characterisation.

Figure 3 (a) Poisson's ratio, $v$ and (b) Young's modulus, E, synthetic values compared against those measured in the vertical pilot well (see online version for colours)

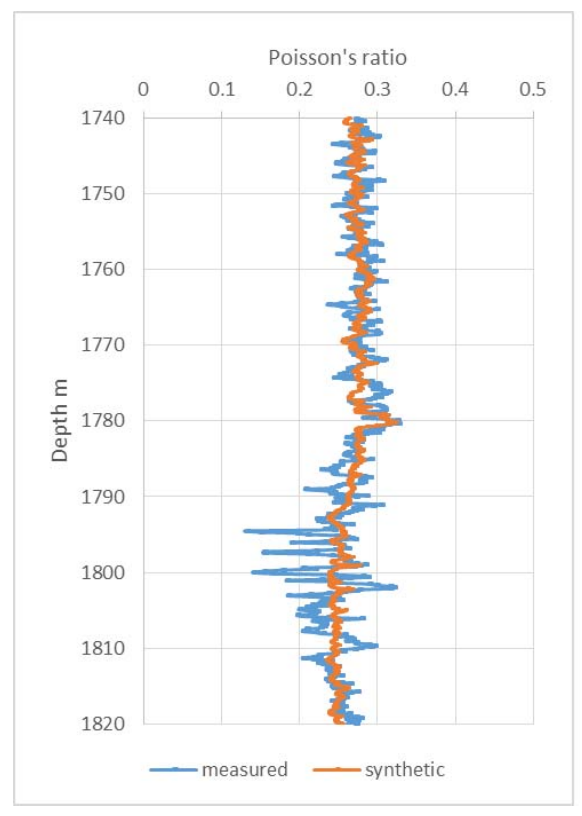

(a)

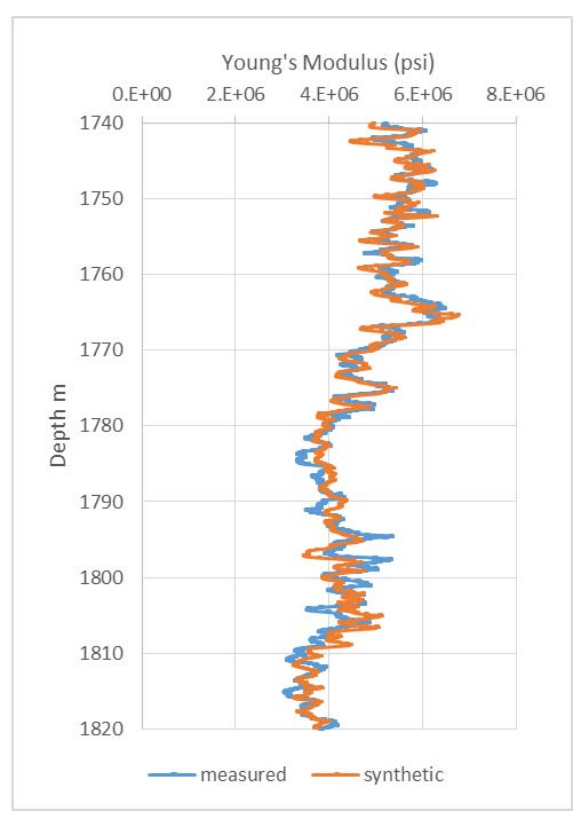

(b)

Figure 4 illustrates acoustic impedance values, $I_{p}=\rho V_{p}$, computed using bulk density readings and velocity of the compressional wave. 
Figure 4 Acoustic impedance $I_{p}$ values computed in the vertical pilot well (see online version for colours)

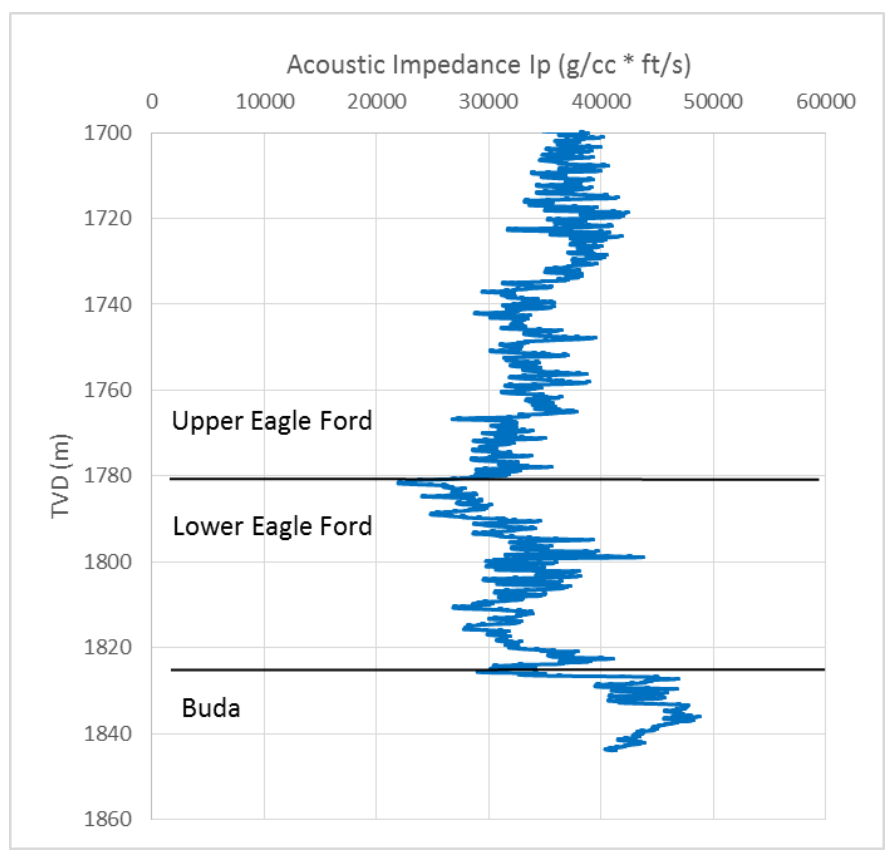

The synthetic acoustic log for the horizontal section was generated once Young's modulus and Poisson's ratio were calibrated as shown previously. The synthetic acoustic $\log$ served to estimate geo-mechanical and geophysical parameters, such as $E, v, B A, I_{p}$, $I_{s}, V_{p} / V_{s}$ ratio, and other rock parameters, along the horizontal section of the wellbore. Profiles of some of these parameters plotted against developed depth (MD) are shown in Figures 5 through 8 . In addition, Figure 9 illustrates gamma ray values recorded while drilling the horizontal well.

Figure 5 Young's modulus, $E$, synthetic values computed along the horizontal section of the wellbore (see online version for colours)

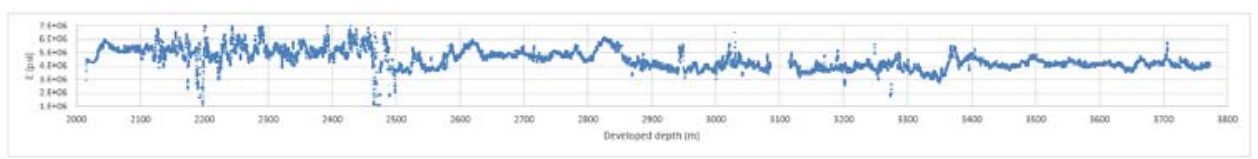

Figure 6 Poisson's ratio, $v$ synthetic values computed along the horizontal section of the wellbore (see online version for colours)

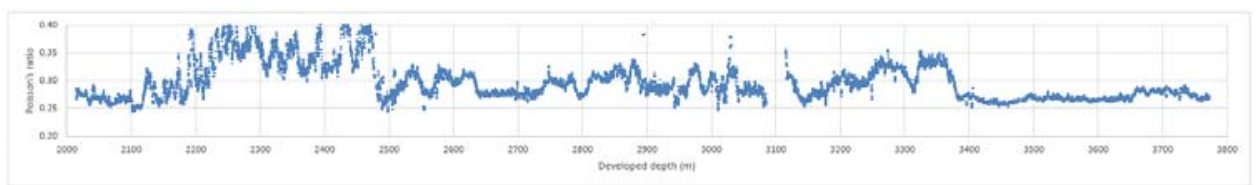


Figure 7 Acoustic impedance, $I_{p}$ synthetic values computed along the horizontal section of the wellbore (see online version for colours)

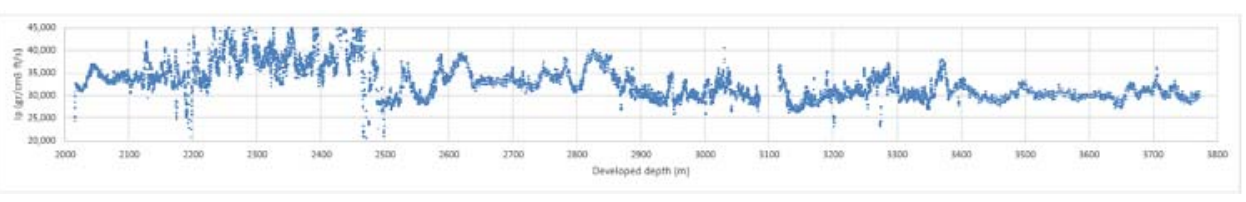

Figure 8 Brittleness average values computed along the horizontal section of the wellbore (see online version for colours)

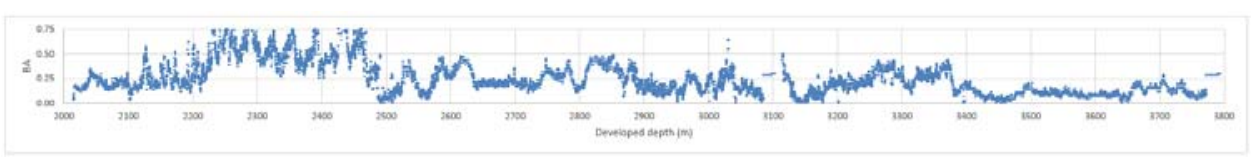

Figure 9 Gamma ray values recorded while drilling the horizontal section of the wellbore (see online version for colours)

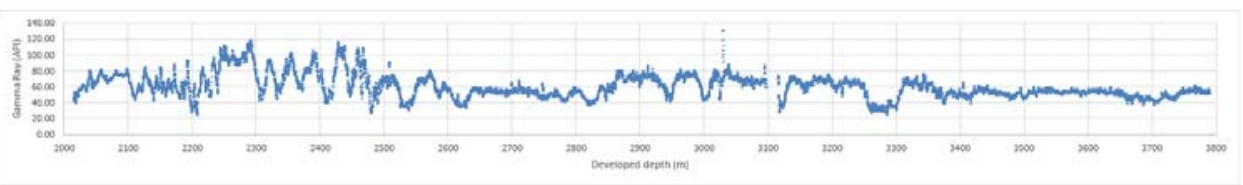

Based on Ogiesoba's statements included in Section 3, we postulate that intervals with high BA values have high CQ, and those intervals with high acoustic impedance possess high RQ. Ogiesoba found direct relationship between acoustic impedance and TOC. Intervals with high CQ and RQ should be considered hydrocarbon sweet spots. We propose that changes in trends of BA and acoustic impedance observed while drilling should be closely monitored to improve decision-making criteria. Reservoir pressure is also an important parameter useful to classify the quality of the reservoir.

Analysis as proposed in this study comes from data acquired with LWD techniques; therefore, real time or close to real time processing of LWD data is highly encouraged. We can see from Figure 7 that average acoustic impedance, $I_{p}$, value close to $38,000 \mathrm{gr} / \mathrm{cm}^{3}-\mathrm{ft} / \mathrm{s}$ was computed in interval 2,200-2,460 m. Beyond this developed depth, the trend of acoustic impedance changes. It decreases to values near $30,000 \mathrm{gr} / \mathrm{cm}^{3}-\mathrm{ft} / \mathrm{s}$ and does not increase to previous values again. This behaviour suggests that the best hydrocarbon sweet spots in this wellbore are confined to the interval 2,200-2,460 m only. This interval must be considered as one with the best RQ.

Review of Figures 5, 6, and 8 demonstrates that BA correlates well with intervals showing high Young's modulus and low Poisson's ratio values. According to BA average values equal to 0.50 , the zone between $2,200-2,460 \mathrm{~m}$ is identified as a brittle interval. Beyond this interval, BA trend changes with values decreasing drastically to averages close to 0.25 , not recovering again the values observed before. When a detailed analysis of these figures is done, BA behaviour seems not to be in agreement with a common approach used to define fracturability of a formation, suggesting that high $E$ and low $v$ values favour fracturability. Explanation to the behaviour seen in interval 2200-2460m can be obtained using different methodologies. Yenugu (2015) and Sayers et al. (2015) suggest the implementation of cross plotting techniques. These cross plotting techniques 
include parameters such as acoustic impedance, shear impedance, $V_{p} / V_{s}$ ratio, and others to distinguish between organic-rich and organic-lean shales and to define RQ and CQ. On the other hand, Perez-Altamar (2013) worked on the influence of TOC on the geo-mechanical behaviour of rock and stated that high values of TOC are in close correlation with high gamma ray readings and high BA values. Bassiouni (1994), among others, explains that there are different factors affecting gamma ray response such as the presence of potassium, thorium, and uranium. The spectral gamma ray log is the appropriate tool to account for these factors to differentiate presence of organic matter from other sources of natural radiation. However, spectral gamma ray tools are not commonly deployed in horizontal wells, and core samples were not collected in this case. Therefore, we implemented Perez-Altamar's approach to continue our analysis.

Gamma ray values shown in Figure 9 indicate that the interval 2,200-2,460 $\mathrm{m}$ has higher gamma ray values than other intervals. GR readings in this interval reach values up to $120 \mathrm{API}^{0}$. Using caution, it can be inferred that high BA values in this interval could be related to the presence of organic matter. Note that Poisson's ratio values depicted in Figure 6 show higher than average values for this particular interval. Figure 10(a) shows a cross plot of GR versus brittleness index associated with TOC as proposed by Perez-Altamar. We cross plotted computed values of GR versus BA in Figure 10(b), which can be compared to Figure 10(a). Figure 10(b) reveals a defined trend allowing us to identify that high TOC values correspond to high brittleness and high gamma ray values. Because TOC is a direct measurement of organic richness, the high GR recorded are in agreement with previous conclusions. High GR values define high presence of organic matter. Therefore, Figure 10(b) serves to conclude that the interval $2,200-2,460 \mathrm{~m}$ is the one with the highest TOC and high RQ.

Figure 10 (a) Cross-plotted values of gamma ray versus brittleness index showing correlation with TOC (b) Cross-plot of GR versus BA in the horizontal well showing brittleness behaviour and its correlation with TOC (see online version for colours)

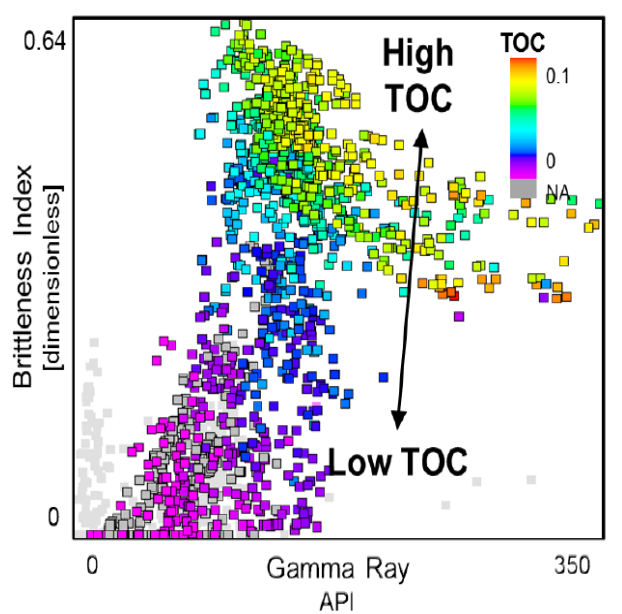

(a)

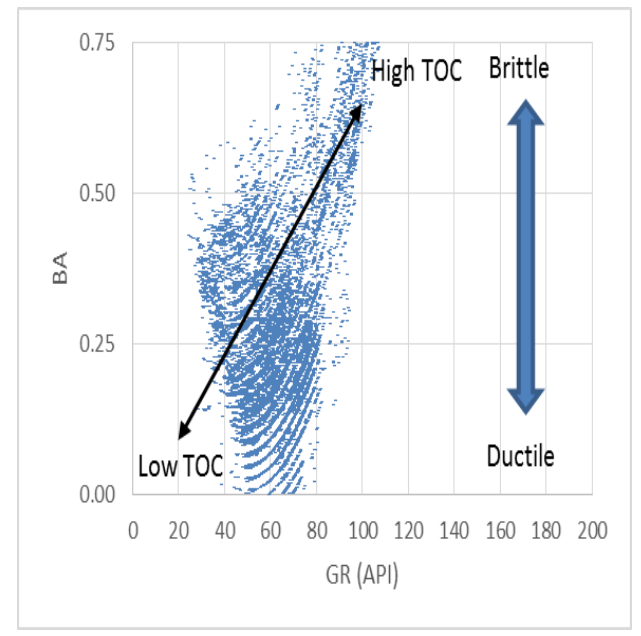

(b)

Source: Perez-Altamar (2013) 


\subsection{Computing reservoir pressure along the horizontal section}

We used the acoustic synthetic log to compute reservoir pressure following the treatment proposed in Section 4. Calibration of reservoir pressure profile was obtained using reservoir pressure measured with a conventional down-hole pressure gauge at Eagle Ford level. Recorded pressure was 3,296 psi. As it can be noticed in Figure 11, reservoir pressure has significant variations. These changes are attributed to the heterogeneity of the formation. An average reservoir pressure close to 3,350 psi can be identified. The interval 2,200 to $2,500 \mathrm{~m}$ shows lower than average pressure. It is suggested that identification of higher and lower than average reservoir pressure intervals is of high relevance to define RQ. It is important to point out that the horizontal well was drilled within the producing formation as proved by the deviation profile of horizontal wellbore shown in Figure 12. Navigation inside Eagle Ford formation was contained within 1,785 to $1,800 \mathrm{~m}$ true vertical depth (TVD).

Figure 11 Computed reservoir pressure, from the diffusivity equation, along the horizontal section of the wellbore (see online version for colours)

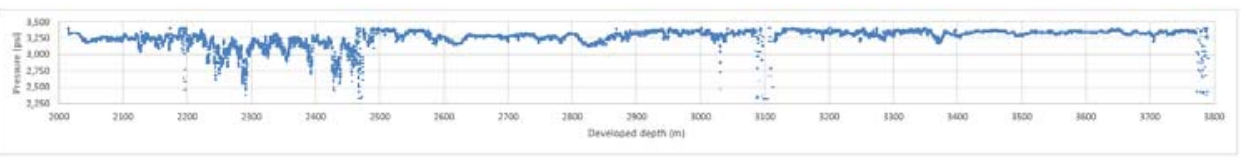

Figure 12 Deviation profile of the complete horizontal section showing navigation within Eagle Ford formation (see online version for colours)

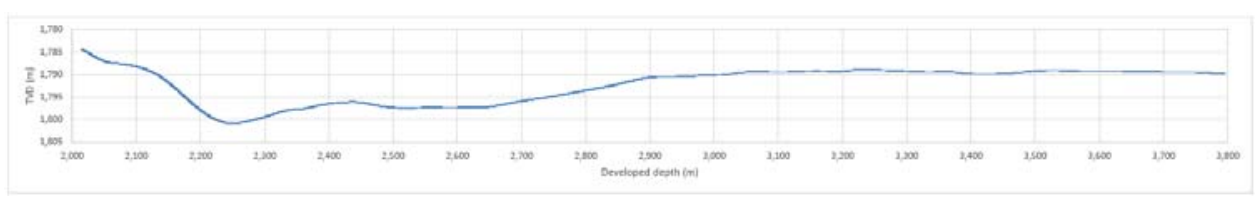

Measuring production flow rate downhole effectively through the entire horizontal wellbore is a practice highly recommended after completion of the well. Using the appropriate tools, equipment, and software, completion effectiveness and post-fracture production from each interval can be accurately measured. This practice would surely help improve completion effectiveness of horizontal wellbores. However, the tools required to accomplish this task were not deployed into this well. Instead, production was computed using conventional measurement surface equipment.

\section{Conclusions}

The results shown in this study demonstrate that hydrocarbon sweet spots in unconventional shale can be identified while drilling the horizontal section of the wellbore. Geo-mechanical and geophysical rock properties and reservoir pressure in the horizontal section of the well were obtained from logging while drilling (LWD) techniques. Based on these parameters, hydrocarbon sweet-spots with high TOC were identified and characterised by high acoustic impedance and high brittleness values. RQ and CQ are closely related to these two rock parameters. Therefore, the conjunction of 
acoustic impedance and brittleness of rock is suggested to identify sweet spots while drilling using LWD technique. These two properties are two powerful parameters to be implemented in hydrocarbon sweet spot identification while drilling in any geologic setting. Reservoir pressure estimation complements an effective identification of hydrocarbon sweet spots.

Identification of parameters required to implement the methodology proposed in this work was accomplished by using information obtained while drilling the horizontal wellbore. Therefore, real time or near to real time processing of LWD information is suggested to improve decision-making. Changes in trends of acoustic impedance and brittleness of rock identify hydrocarbon sweet spots.

Adequate identification of hydrocarbon sweet spots will help to improve completion activities, to optimise the length of the horizontal section of the well, and ultimately to improve horizontal well performance.

\section{Nomenclature}

\begin{tabular}{ll}
\hline$A, B, C$ & constants \\
$B A$ & brittleness average, dimensionless \\
$C_{f}$ & fluid compressibility, $1 / \mathrm{psi}$ \\
$C_{r}$ & pore volume compressibility, $1 / \mathrm{psi}$ \\
$E$ & Young's modulus, psi \\
$E_{\text {brittleness }}$ & normalised Young's modulus, dimensionless \\
$E_{\text {max }}$ & maximum Young's modulus reading, psi \\
$E_{\min }$ & minimum Young's modulus reading, psi \\
$E_{s}$ & stored energy in the system, energy units \\
$G R$ & gamma ray readings, API units \\
$I_{p}$ & acoustic impedance, gr/cm ${ }^{3} * \mathrm{ft} / \mathrm{sec}$ \\
$I_{s}$ & shear impedance, gr/cm ${ }^{3} * \mathrm{ft} / \mathrm{sec}$ \\
$k$ & formation permeability, mDarcies \\
$L$ & depth of investigation, $\mathrm{m}$ \\
$P$ & formation pore pressure, $\mathrm{psi}$ \\
$Q$ & instantaneous quality factor, dimensionless \\
$R H O B$ & bulk density, gr/cm ${ }^{3}$ \\
$r_{o}$ & formation resistivity, ohm-m \\
$t$ & time, sec (min) \\
$T O C$ & total organic content/carbon, fraction \\
$V_{p}$ & velocity of the compressional wave, $\mathrm{ft} / \mathrm{s}$ \\
$V_{s}$ & velocity of the shear wave, $\mathrm{ft} / \mathrm{s}$ \\
$z$ & depth of interest, $\mathrm{m}$ \\
$\Delta t_{\text {avg }}$ & sonic average interval travel time, $\mu \mathrm{sec} / \mathrm{ft}$ \\
$\Delta t_{o}$ & sonic interval travel time $(\mathrm{ITT}), \mu \mathrm{sec} / \mathrm{ft}$ \\
$\Delta t_{p}$ & compressional sonic interval travel time $(\mathrm{ITT})(\mu \mathrm{sec} / \mathrm{ft})$ \\
\hline &
\end{tabular}




\section{Nomenclature (continued)}

\begin{tabular}{ll}
\hline$\Delta t_{s}$ & shear sonic interval travel time $(\mathrm{ITT})(\mu \mathrm{sec} / \mathrm{ft})$ \\
$\lambda$ & eigenvalues in the solution of the diffusivity equation \\
$\lambda_{L}$ & Lamé parameter of incompressibility, $\mathrm{gr} / \mathrm{cm}^{3} *(\mathrm{ft} / \mathrm{sec})^{2}$ \\
$\rho$ & bulk density of rock, $\mathrm{gr} / \mathrm{cm}^{3}$ \\
$\theta$ & porosity, fraction \\
$\mu$ & fluid dynamic viscosity, cp \\
$\mu_{L}$ & Lamé parameter of rigidity, gr $/ \mathrm{cm}^{3} *(\mathrm{ft} / \mathrm{sec})^{2}$ \\
$v$ & Poisson's ratio, dimensionless \\
$v_{\text {brittleness }}$ & normalised Poisson's ratio, dimensionless \\
$v_{\text {max }}$ & maximum Poisson's ratio reading, dimensionless \\
$v_{\min }$ & minimum Poisson's ratio reading, dimensionless \\
$\omega$ & oscillatory frequency, sec \\
\hline
\end{tabular}

\section{References}

Baldino, S., Rafieepour, S. and Miska, S.Z. (2017) 'In-situ Poisson's ratio determination under different deformational conditions', Paper SPE 185112-MS prepared for presentation at the SPE Oklahoma City Oil and Gas Symposium, Oklahoma City, 27-31 March.

Bassiouni, K. (1994) Theory, Measurement and Interpretation of Well Logs, First printing SPE Textbook Series Vol. 4., Richardson, TX.

Chopra, S. and Pruden, D. (2003) 'Multi-attribute seismic analysis on AVO-derived parameters - a case study', The Leading Edge, September, Vol. 22, No. 10, pp.998-1002.

Colin, C.P. and Darren, S.F. (1997) Formation Elastic Parameters by Deriving S-wave Velocity Logs, CREWES Research Report, Vol. 9, pp.10-13.

Economides, M.J., Hill, D.A., Ehlig-Economides, C. and Zhu, D. (2013) Petroleum Production Systems, 2nd ed., Pearson Education Inc., Prentice Hall, Massachusetts, USA.

Economides, M.J., Watters, L.T. and Dunn-Norman, S. (1998) Petroleum Well Construction, 1st ed., John Wiley \& Sons Ltd., Chichester, England.

Elapavuluri, P. and Bancroft, J. (2004) 'Estimation of Q using cross correlation', CSEG National Convention, CREWES, University of Calgary, Calgary.

Fjaer, E., Holt, R.M., Horsrud, P., Raaen, A.M. and Risnes, R. (2008) Petroleum Related Rock Mechanics, 2nd ed., Elsevier, The Netherlands.

Glaser, K.S. et al. (2014) 'Seeking the sweet spot: reservoir and completion quality in organic shales', Oilfield Review, Winter 2013/2014, Schlumberger, Vol., 25, No. 4., pp.16-29.

Grieser, B. and Bray, J. (2007) 'Identification of production potential in unconventional reservoirs', Paper SPE 106623, Presented at the SPE Production and Operations Symposium, Oklahoma City, Oklahoma, USA, 31 March-3 April.

Guo, Z., Li, X. Liu, C. Feng, X. and Shen, T. (2013) 'A shale rock physics model for analysis of brittleness index, mineralogy and porosity in the Barnett Shale', Journal of Geophysics and Engineering, February, Vol. 10, No. 2, 025006.

Herwanger, J.V., Bottrill, A.D. and Mildren, S.D. (2015) 'Uses and abuses of the brittleness index with applications to hydraulic stimulation', Paper was prepared for presentation at the Unconventional Resources Technology Conference (URTeC), San Antonio, Texas, 20-22 July, DOI: 10.15530/urtec-2015-2172545. 
Jansen, T.A. (2014) The Effect of Rock Properties on Hydraulic Fracture Conductivity in the Eagle Ford and Fayetteville Shales, MS thesis in Petroleum Engineering, submitted to the office of Graduate and Professional Studies of Texas A\&M University, Texas, December.

Lopez, A. and Sepehrnoori, K. (2015) 'The diffusivity equation for geopressure prediction using well logs', Journal of Petroleum Science and Engineering (JPSE), October, Vol. 134, pp.186-198 [online] http://dx.doi.org/10.1016/j.petrol.2014.10.009.

Lu, J., Tiab, D. and Escobar, F.H. (2013) 'Productivity equation for a horizontal well inside a closed-anisotropic box-shaped reservoir under pseudosteady-state conditions', Journal of Engineering and Applied Sciences, Asian Research Publishing Network (ARPN), June, Vol. 8, No. 6, pp.425-434.

Miller, D., Horne, S. and Walsh, J. (2011) 'Precise estimation of elastic moduli from sonic log data in a gas shale formation', Presented at the 1st International Workshop in Rock Physics, Golden Colorado, 7-12 August.

Montaut, A., Sayar, P. and Torres-Verdin, C. (2013) 'Detection and quantification of rock physics properties for improved hydraulic fracturing in hydrocarbon-bearing shale', Presented at the SPWLA 54th Annual Logging Symposium, The University of Texas at Austin, 22-26June.

Ogiesoba, O. (2014) 'Seismic multi-attribute analysis for shale gas/oil within the Austin Chalk and Eagle Ford Shale in a submarine volcanic terrain, Maverick Basin, South Texas, Search and Discovery Article \#10601 Presented at GTW-AAPG/STGS Eagle Ford Plus Adjacent Plays and Extensions Workshop, San Antonio, Texas, 24-26 February.

Ogiesoba, O. (2015) 'Application of the instantaneous quality factor (Q) in the characterization of the Austin Chalk and Eagle Ford Shale, South Texas', Search and Discovery Article \#41781 Presented at Geoscience Technology Workshop Unconventional, Bureau of Economic Geology, The University of Texas, Austin, Texas, 3 November.

Parra, J.O. and Domaschk, D. (2009) 'Reading the rocks, technology today', Southwest Research Institute Internal Research Program, Summer [online] http://southwestresearchinstitute.com/ 3pubs/ttoday/Summer09/PDFs/Rocks.pdf (accessed 11 September 2015).

Perez-Altamar, R. (2013) 'Brittleness estimation from seismic measurements in unconventional reservoirs: application to the Barnett Shale', $\mathrm{PhD}$ dissertation submitted to the Graduate Faculty University of Oklahoma, Norman, Oklahoma.

Rickman, R., Mullen, M., Petre, E., Grieser, B. and Kundert, D. (2008) 'A practical use of shale petrophysics for stimulation design optimization: all shale plays are not clones of the Barnett Shale', Paper SPE: 115258 Presented at the SPE Annual Technical Conference and Exhibition, Denver, Colorado, USA, 21-24 September [online] http://dx.doi.org/10.2118/115258-MS.

Sayers, C.M, Fisher, K. and Walsh, J.J. (2015) 'Sensitivity of P- and S-impedance to the presence of kerogen in the Eagle Ford Shale', The Leading Edge, Special Section: Resource Plays II: Geophysics, December, Vol. 34, No. 12, pp.1482-1486.

Shahri, M.P. and Miska, S.Z. (2015) 'In-situ Poisson's ratio determination from interference transient well test', SPE Journal, Vol. 20, No. 5, pp.1-41.

Sone, H. and Zoback, M.D. (2013) 'Mechanical properties of shale-gas reservoir rocks - part 1: static and dynamic elastic properties and anisotropy, Geophysics, September-October, Vol. 78, No. 5, pp.D381-D392.

Yenugu, M. (2015) 'Geophysical and geo-mechanical rock property templates for source rocks', Presented at the SEG 2015 New Orleans Annual Meeting, Ikon Science Americas, USA.

Zhang, J. and Bentley, L. (2005) Factors Determining Poisson's ratio, Consortium for Research in Elastic Wave Seismology (CREWES) Research Report, Vol. 17 [online] https://crewes.org/ForOurSponsors/ResearchReports/2005/2005-62.pdf (accessed 21 September 2012). 